\title{
DEL MUNDO DEL CONSUMO AL CONSUMO-MUNDO. LIPOVESTKY Y LAS PARADOJAS DEL CONSUMISMO INDIVIDUALISTA Y DEMOCRÁTICO
}

\author{
José Francisco Durán Vázquez \\ Universidad de Vigo
}

Resumen: En este artículo se describen las ideas fundamentales del pensamiento de Lipovestky, mostrando como el consumo se ha convertido en su obra en un fenómeno total, válido para interpretar casi cualquier aspecto de la realidad social. Se concluye diciendo que, aunque sus interpretaciones están llenas de ideas ricas y sugerentes sobre la sociedad contemporánea, también se han simplificado en exceso al vincular casi todos los hechos sociales, por más contradictorios que estos sean, a la causa común del consumo, no analizando con el debido rigor y la debida profundidad muchos de los fenómenos que describe.

Palabras clave: Lipovestky, consumo, individualismo, paradojas

From the world of the consumption to the consumption -world. Lipovestky and the paradoxes of the individualism and democratic consumerism

\begin{abstract}
In this article there are described the fundamental ideas of Lipovestky's thought, showing as the consumption it has turned into his work into a total, valid phenomenon to interpret almost any aspect of the social reality. It ends up by being said that, though his interpretations are full of rich and suggestive ideas on the contemporary society, also have been simplified in excess on having linked almost all the social facts, for more contradictory than these be, to the common reason of the consumption, not analyzing with the due rigour and severity many of the phenomena that it describes.
\end{abstract}

Keywords: Lipovestky, consumption, individualism, paradoxes

\section{INTRODUCCIÓN}

El consumo es quizás uno de los fenómenos que más relevancia han cobrado en las sociedades occidentales desde la segunda mitad del siglo XX. En el transcurso de este periodo ha pasado de ser una actividad de la que participaban fundamentalmente las élites a formar parte del estilo de vida del común de las gentes. En este contexto se ha producido un desarrollo sin precedentes de las obras consagradas a su estudio, entre las que cabe destacar especialmente la de Lipovestky.

El ensayista francés se ha distinguido desde la aparición de sus primeras obras en la primera mitad de los años 80 del siglo pasado, por atribuir al consumo un papel determinante en la configuración de la estructura social y del orden normativo de las sociedades postmodernas. En su opinión si estas sociedades son profundamente individualistas y democráticas; si la búsqueda de la felicidad y del bienestar se han convertido en una de las principales metas de la vida de sus 
miembros, es sin duda alguna por la influencia todopoderosa del consumo. Aunque a él se deban también las frustraciones, las insatisfacciones y las angustias que padecen quienes no encuentran la ansiada plenitud en este mundo.

En sus últimas obras Lipovestky ha continuado perfilando el retrato de las sociedades occidentales guiado por las mismas ideas que ya expusiera en su primer ensayo. Tan convencido está de que el espíritu del consumo ha invadido todas las esferas, que apenas queda un ámbito de la realidad social que no pueda ser analizado a partir de este fenómeno. Todo lo que acontece parece tener su huella, nada parece poder ser explicado sin invocar su presencia.

Cabe preguntarse, sin embargo, una vez transcurridas casi tres décadas de la aparición de sus primeros escritos, si el consumo tiene la importancia que él le atribuye. Dicho de otro modo, ¿es el consumo un hecho total a partir del cual pueda leerse cualquier aspecto de la realidad, o esas realidades tienen también su propia dinámica dentro del proceso de construcción de las sociedades modernas? Sostener lo cual no supone negar la influencia enorme que ha tenido este fenómeno en la configuración de estas sociedades, pero acaso esta influencia haya que relativizarla, pues el consumo, como todas las realidades que según el autor francés están influidas por él, forma parte también de un universo más vasto, el que emergió con la modernidad, y es en este contexto en el que hay que interpretarlas.

En el artículo que ha continuación presentamos se exponen las ideas fundamentales del pensamiento de Lipovestky, poniendo de manifiesto como el consumo se ha convertido en su obra en el principio explicativo clave de casi todas las transformaciones y de casi todos los fenómenos ocurridos en las sociedades occidentales desde la segunda mitad del siglo XX, por contradictorios que ellos sean. Concluiremos mostrando como esta tendencia a hacer de este aspecto de la realidad el principal factor interpretativo, si bien ha enriquecido sus escritos con brillantes intuiciones y sugerencias sobre las sociedades contemporáneas, también los ha empobrecido, al no analizar con rigor los fenómenos que describe, vinculándolos todos ellos el universo total del consumo.

Comencemos pues por desgranar las ideas principales de su obra, no sin antes referirnos a las fuentes de su pensamiento.

\section{ORIGEN Y METAMORFOSIS DE UN PENSAMIENTO}

Lipovestky nació en París 1944, en donde estudió filosofía en la Sorbona, dedicándose durante varios años a la docencia de esta materia, primero en el Liceo de Orange y más tarde en la universidad de Grenoble.

Se dio a conocer al mundo como ensayista en 1983 con "la era del vacío", a la que siguieron muchas otros ensayos en los que trataba de analizar el universo de las sociedades postmodernas. 
Desde el punto de vista intelectual Lipovestky, como muchos otros miembros de su generación, incorporó en un principio la herencia marxista, aunque más tarde fuese muy crítico con ella (Lipovestky, 2006: 116). En ese viaje desde el marxismo irá bebiendo de diversas fuentes, desde Freud y el estructuralismo de Bourdieu, Levy-Strauss y Foucault, hasta Catoriadis, Nietzsche, Lyotard, Baudrillard o Deleuze (Lipovestky, 2006: 117-18). Más tarde, su pensamiento dará un giro sustancial a partir de la lectura de obras como las de Marcel Gauchet, Louis Dumont, Claude Lefort, François Furet, Luc Ferry, Daniel Bell y, por supuesto, la de Tocqueville, cuya influencia, según el mismo reconoce, será palpable en "la era del vació" (Lipovestky, 2006: 118-19; 2008: 16-17). Desde ese momento se alejará de los análisis estructuralistas de la sociedad centrados en la disciplina, el control y la competencia por el estatus, al entender que las sociedades postmodernas, en las que el consumo ocupaba un lugar preponderante, estarían más caracterizadas por el individualismo, el igualitarismo y el hedonismo (Lipovestky, 2006: 118-19; 2008: 16-17).

Desde esta perspectiva desarrollará su pensamiento con un particular estilo, en el que hay una acentuada tendencia a jugar con dos o tres ideas que son la matriz de toda una argumentación entreverada de paradojas, con las que compone un fresco de la sociedad contemporánea.

En lo que sigue mostraremos más en profundidad las principales líneas de su pensamiento, comenzando para ello con "la era del vacío", obra que lo convirtió en una de las figuras más célebres del panorama intelectual contemporáneo, y en la que sintetiza todas las ideas que desarrollará en textos posteriores.

\section{LA ERA DEL VACÍO}

Lipovestky se dio a conocer intelectualmente con el ensayo titulado "La era del vacío", publicado por primera vez en 1983. En él relataba el proceso de transformación de las sociedades de consumo occidentales a partir de la Segunda mitad del siglo XX. Esta transformación inauguraba, en su opinión, una nueva era marcada por una fuerte exacerbación de los valores individualistas e igualitaristas encumbrados por la primera modernidad, para instaurar un nuevo orden social, característico de la postmodernidad, mucho más persuasivo, personalizado, electivo y hedonista, en franca ruptura con el orden jerárquico y disciplinario de la etapa anterior. Se ponía así fin a aquel equilibrio, todavía imperante en la primera fase de la modernidad, entre la esfera institucional y la individual, emergiendo esta última como vector principal de la nueva organización social.

Este cambio en la forma de organizar la sociedad, en los valores y en las actitudes de sus miembros, estaba para Lipovestky estrechamente vinculado con la expansión del consumo como fenómeno global, como fenómeno de masas, desde los años 60 del siglo pasado. El consumo, en efecto, llevaría al extremo el proceso de individualización y democratización de las sociedades occidentales, reemplazando el imaginario social moderno edificado alrededor de la idea de 
progreso, identificada con los deseos de emancipación individual en el marco de una sociedad secularizada y meritocrática articulada entorno a las clases. Huérfanos de ideologías motivadoras y movilizadoras y volcados en la esfera del consumo, los individuos postmodernos reificarían sus propias experiencias como polos de una identidad vacía de grandes proyectos, pero plena de vitalismo y de hedonismo, de deseo de expresar la propia individualidad en comunión con otros sujetos.

Este panorama social que dibuja Lipovestky en la "era del vacío", en el que conviven la desafección por lo institucional con la afirmación de una personalidad hedonista, explicaría toda una serie de comportamientos y de actitudes observables en las sociedades postmodernas.

Explicaría la renuncia a todo orden coercitivo y autoritario, que todavía encontraba su lugar en la primera modernidad al servicio de la emancipación y la liberación personal. En lugar de este orden se apelaría ahora a la seducción, al individualismo, a la comunicación y a la participación en casi todas las esferas sociales; desde la política al mundo del trabajo, desde la educación a la familia (Lipovestky, 1986: 17 y ss).

Explicaría también la indiferencia de los sujetos con respecto a los diferentes ámbitos institucionales, en virtud del escepticismo con el que perciben sus proyectos colectivos (Lipovestky, 1986: 43 y ss).

En medio de este vacío se erige el individuo postmoderno, ansioso por manifestar su personalidad a través del consumo, pero también cada vez más inseguro. Una inseguridad que no es sino el resultado de su propia autonomía, de haber relajado sus vínculos con las distintas instancias colectivas, no pudiendo ya curar sus heridas si no es recurriendo a terapias psicológicas de distinto signo. Terapias que lo restauren en su subjetividad, que es al mismo tiempo la fuente de su propia fragilidad. "Cada uno- concluye Lipovestky- exige estar sólo, cada vez más sólo y simultáneamente no se soporta a sí mismo..." (Lipovestky, 1986: 48).

La figura de esta nueva subjetividad postmoderna, triunfante y débil al mismo tiempo, es Narciso. Narciso es, en efecto, para Lipovestky "el símbolo de nuestro tiempo" (Lipovestky, 1986: 49). Encarna al sujeto que vive para si mismo sin ningún sentido del tiempo histórico, y por ello también absolutamente volcado en el presente. Representa una nueva autoconciencia que no reconoce ninguna autoridad exterior a sí misma, y que por ello manifiesta también una menor intensidad moral y una mayor indiferencia (Lipovestky, 1986: 67).

No obstante, se apresura a aclarar nuestro autor, esta actitud no anuncia ninguna convulsión social. Si bien supone un cierto debilitamiento del espacio público, no hace temer por ello la llegada de ningún autoritarismo (Lipovestky, 1986: 57). El individualismo postmoderno es, por el contrario, profundamente democrático (Lipovestky, 1986: 129). Lo es porque es hijo del espíritu igualitario moderno, acentuado y multiplicado en la postmodernidad por unas mismas aspiraciones de bienestar material y sensual, y por ello también por una misma voluntad de 
mostrar la particularidad y la diferencia, pero sin ninguna carga ideológica, sin ninguna intención de defender posturas extremas y conflictivas. Al contrario, el individualismo postmoderno es descreído, pero no es el descreimiento de la negación absoluta, de la crítica corrosiva, y mucho menos una huida del mundo. Se conjuga más bien con una actitud cool, irónica y humorística, hedonista y festiva (Lipovestky, 1986: 136 y ss). Por esta misma razón las sociedades postmodernas son esencialmente pacifistas, ya que sus miembros están tan preocupados por su bienestar material y su felicidad, y tan centrados en sí mismos, que huyen de todo enfrentamiento con sus semejantes, de toda violencia (Lipovestky, 1986: 198-99). Lo cual no quiere decir que la violencia se haya erradicado por completo. En efecto, matiza el pensador francés, la imposibilidad de ver realizadas las aspiraciones cada vez más democráticas de satisfacción y de desarrollo personal en un mundo cada vez más desregulado e individualista, empuja a los más marginados a la delincuencia, y a otros al suicidio (Lipovestky, 1986: 206 y ss).

Así completa Lipovestky su retrato de las sociedades postmodernas, un retrato que irá perfilando en sus obras posteriores a partir del análisis de una serie de fenómenos que no serían si no la expresión de lo que estaba ya anunciado en "la era del vacío". La moda es, en su opinión, el ejemplo "más significativo" de estos fenómenos porque sintetiza perfectamente los valores imperantes en las sociedades postmodernas.

\section{LA MODA COMO EXPRESIÓN DE LA DINÁMICA INDIVIDUALISTA E IGUALITARISTA}

La moda es, en efecto, para Lipovestky uno de los ámbitos privilegiados para analizar las actitudes y los comportamientos predominantes en las sociedades postmodernas. Su estudio se revela por tanto indispensable para conocer más de cerca este universo, con todas sus ambigüedades y sus contradicciones, con todos sus acentos.

Según nuestro autor, hablando con propiedad, no puede considerarse que haya moda antes del advenimiento del mundo moderno, entendiendo por tal esa formación socio-histórica que comienza a emerger en las postrimerías de la Edad Media (Lipovestky, 1990: 23). Con anterioridad a este momento el respeto por la tradición era la norma dominante impidiendo todo intento de renovación, y por tanto la eclosión de la moda como fenómeno social relevante.

A partir de aquí se abriría sin embargo una nueva época, jalonada por una serie de etapas, en la que la moda alcanzará un protagonismo antes desconocido. El primer periodo de este nuevo ciclo histórico, denominado por Lipovestky "momento aristocrático", dará comienzo a finales de la edad Media.

Momento Aristocrático porque la nobleza adopta la moda como signo de distinción social, como símbolo de una nueva identidad cortesana, como artificio necesario en un mundo de apariencias. Esta moda aristocrática, profundamente elitista, se 
convertirá pronto en un modelo a imitar por las nuevas clases burguesas en ascenso (Lipovestky, 1990: 42 y ss). La moda adquirirá en este contexto un doble significado. Por una parte, presenta una fuerte condición jerárquica; por la otra permite una mayor originalidad y una aproximación entre los grupos sociales, aunque el juego de imitaciones se reduzca básicamente a la burguesía y a la nobleza. Desde este último punto de vista, la indumentaria, el adorno, y en general todo lo estético, prefiguran ya un universo social mucho más igualitarista e individualista, si bien este individualismo y este igualitarismo se pliegan todavía a las convenciones jerárquicas y estamentales (Lipovestky, 1990: 52).

Ahora bien, se dispone a aclarar Lipovestky, si bien la moda así entendida es el producto de la competición entre los distintos estratos sociales por mantener su estatus, cuya continuidad histórica es por otra parte evidente, y desde luego muy anterior a su profusión social, su novedad radica en que supuso un cambio de valores en la historia de Occidente, cambio que comienza a ser perceptible a partir de la segunda mitad del siglo XIV en la nobleza cortesana y más tarde en la alta burguesía, y que se caracterizó por la emergencia de una nueva conciencia de la individualidad y de la originalidad, de una nueva actitud ante la vida más pegada al refinamiento estético y a los placeres mundanos. Esta nueva actitud y esta nueva conciencia promoverán finalmente la ruptura con la tradición, la apertura a la innovación y el deseo de exhibir la propia personalidad, una de cuyas manifestaciones más notables será el gusto acentuado por el atuendo y en general por la moda (Lipovestky, 1990: 64 y ss).

La moda Aristocrática, tal como la define Lipovestky, cerrará su ciclo en la primera mitad del siglo XIX. Se inaugura así una larga etapa, la de "la moda centenaria", que perdurará hasta los años 60 del siglo XX, etapa en la que la moda adquirirá un carácter mucho más moderno (Lipovestky, 1990: 76 y ss).

En primer lugar, porque se convertirá en parte de una gran industria, cuyo centro será París, en la que conviven la Alta Costura, mucho más artesanal e identificada con determinados creadores, y la confección industrial. En segundo lugar, porque al ser una industria, la moda se hace más estandarizada y planificada, acelerando los procesos de creación y de innovación permanentes. Finalmente, en la medida en que deja de ser una moda elitista para abrirse a otros grupos sociales con aspiraciones más individualistas y democráticas, tornándose así más uniforme y homogénea y con una menor inclinación al oropel ostentoso, pero también más heterogénea y diversa para complacer así los deseos de personalización de los nuevos clientes (Lipovestky, 1990: 77 y 107-108).

No obstante, esta tendencia democrática no difuminó por completo la simbología jerarquizadora de la moda. Ésta persistió, aunque de un modo más suave, menos marcado, en un mundo como el moderno en el que la exhibición ostentosa ya no gozaba del mismo predicamento (Lipovestky, 1990: 84). Como persistió también la diferenciación entre los sexos, toda vez que la moda centenaria estaba dirigida fundamentalmente a la mujer, en correspondencia con una época en la que todavía es visible la diferencia de roles entre los géneros, estando reservada a la 
mujer una función más seductora y estética, y al hombre, sin embargo, otra más productiva y austera (Lipovestky, 1990: 101).

A la moda centenaria, con su doble faz jerárquica y aristocrática, democrática e individualista, le sucederá a partir de los años 60 del siglo XX otra fase, llamada por Lipovestky "la moda abierta", dominada por el fenómeno del prêt-à-porter, que rompe con las tendencias más aristocráticas de la etapa anterior, a la vez que acentúa aquellas otras más democráticas e individualistas. Se instaura así una moda producida industrialmente, al alcance de todo el mundo, de la que ya participa activamente el hombre, y que está pendiente de todas las innovaciones y de todos los cambios de estilo. Una moda consustancial al desarrollo de una clase media con más recursos y más móvil, pero también al de una nueva juventud, la del Baby-Boom, ansiosa por expresar a través de la ropa sus valores más contraculturales, hedonistas, democráticos y libertarios. Comienzan así a proliferar una variedad de estilos, protagonizados sobre todo por los más jóvenes, que quieren comunicar por medio de las modas su particular código de identidad (Lipovestky, 1990: 132 y ss).

El prêt-à-porter aúna de este modo unas mismas aspiraciones democráticas e individualistas. Un mismo interés por buscar la particularidad y la individualidad a través de la indumentaria. $Y$ todo ello menos por pretensiones clasistas que por exhibir la propia personalidad sin complejos, de una manera desenfadada, autónoma y libre (Lipovestky, 1990: 165).

El triunfo de la moda, la "moda plena" en palabras de Lipovestky, representa precisamente la propagación de estos valores por todas las capas sociales y por casi todos los ámbitos de la realidad social; no sólo en el vestido, sino también en la política y en el mundo de la cultura o en el de los medios de comunicación, e incluso en el de las ideologías. Todo está penetrado por este mismo espíritu. Por todas partes y en todas partes, observa el autor francés, existe una propensión semejante al hedonismo, a la afirmación de la autonomía y de la personalidad, a la libertad de elección, a la renovación permanente de los gustos y de los estilos de vida (Lipovestky, 1990: 206-207). Propensión que contribuye a socavar las formas de vida tradicionales y los grandes discursos ideológicos de la primera modernidad, instaurando una cultura más electiva y opcional, pero también más frágil y superficial (Lipovestky, 1990: 251 y ss).

La publicidad y los medios de comunicación producen los grandes discursos destinados a alimentar todos estos anhelos, presentes ya en los distintos grupos sociales, mediante la comunicación y la seducción persuasivas (Lipovestky, 1990: 210 y ss). No obstante, Lipovestky se aleja aquí de cualquier criticismo. Si bien es cierto que estos medios fomentan una cultura más orientada al entretenimiento, y por ello más superficial y ligera, también lo es que crean un ambiente más racional y crítico, en la medida en que ponen a disposición del ciudadano medio distintas opiniones y visiones de la realidad que antes escapaban a su conocimiento (Lipovestky, 1990: 268-69). Dicho de otro modo, el reino de la moda, desde el momento en que rinde culto al individualismo, a la libertad y a la igualdad, 
contribuye solidamente a reforzar el espíritu democrático. "La moda plena- escribe Lipovestky- no es un obstáculo para las autonomías de las conciencias, es la condición de un movimiento de masa hacia las Luces" (Lipovestky, 1990: 298). Y precisamente por ello, por consolidar y legitimar la democracia, la moda es, a pesar de sus excesos individualistas y narcisistas, más una fuerza integradora que disgregadora, una fuerza que favorece la consolidación de las sociedades democráticas (Lipovestky, 1990: 311 y ss).

Sin embargo, desde el momento en que sacraliza al sujeto y lo remite a sus propias insatisfacciones e inseguridades personales, la moda favorece también la depresión y la angustia (Lipovestky, 1990: 324).

En suma, la moda presenta ese carácter ambiguo que Lipovestky atribuye a las sociedades postmodernas. Promueve la igualdad entre los hombres; es fuente de independencia, de libertad y de solidaridad; y al mismo tiempo crea numerosas inseguridades y crisis existenciales a un sujeto como el moderno que se considera el artífice y el protagonista de su propia existencia.

Desde este punto de vista las actitudes ante la moda y ante el consumo en general, contribuyen en buena medida a configurar el orden moral de las sociedades occidentales, un orden basado en la afirmación de los valores democráticos, igualitaristas e individualistas.

\section{LA "ÉTICA INDOLORA" POSTMODERNA: DE LA MORAL UNIVERSALISTA DEL DEBER A LA ÉTICA INDIVIDUALISTA DE LOS DERECHOS SUBJETIVOS}

En las sociedades postmodernas dominadas por el consumo emergería, en opinión de Lipovestky, un nuevo universo moral derivado en gran parte de los valores consagrados por la propia sociedad de consumo (Lipovestky, 1994: 50). Esta moral sustituiría las normas más universalistas, rigoristas y autoritarias de la primera modernidad, que conjugaban los derechos individuales con los deberes hacia la comunidad, por otras más individualistas, persuasivas y hedonistas. En efecto, cuando los grandes relatos encumbrados por la modernidad, que invocaban las obligaciones de los individuos hacia la nación, el trabajo o la familia, han perdido su fuerza vinculante anterior, es cuando los derechos subjetivos se convierten en el principal polo de referencia de la nueva moral encumbrada por las sociedades de consumo. Este nuevo orden moral, calificado por Lipovestky de postmoralista, aludiría, en fin, a una realidad en la que "la idea de sacrificio de sí está socialmente deslegitimada, en que la moral ya no exige consagración a un fin superior a uno mismo, en que los derechos subjetivos dominan los mandamientos imperativos" (Lipovestky, 1994: 48).

Postmoralista, puntualiza Lipovestky, no quiere decir sin embargo sin moral, significa ante todo que el individuo y sus aspiraciones de bienestar material y espiritual se convierten en la categoría central del nuevo universo ético legitimado por las sociedades de consumo (Lipovestky, 1994: 48; 2003: 38-39). De ahí que 
convivan en estas sociedades una mayor libertad e iniciativa individual con una creciente reprobación moral de todo lo relacionado con la vulneración de los derechos individuales. En otras palabras, lo que se proclama apelando a los derechos del sujeto soberano se rechaza también en su nombre. El individualismo no se opone, pues, al humanismo, antes bien constituye su auténtico sustrato. No conlleva tampoco la negación del altruismo, sino su revitalización en el ámbito de una cultura individualista, sentimentalista y hedonista teatralizada por los mass media (Lipovestky, 1994: 134 y ss). Y, sobre todo, no implica de ningún modo el cuestionamiento de los valores democráticos, sino su afirmación en el marco de una cultura igualitarista que proclama la autonomía y la libertad como sus valores esenciales (Lipovestky, 2008: 62).

Este moralismo "neoindividualista", más libertario, permisivo, hedonista y democrático, es perceptible en los más diversos ámbitos. En la vida emocional y sexual son cada vez menos frecuentes las condenas y las reprobaciones, se habla con más libertad de estas cuestiones y se aceptan también más las conductas que son fruto de la libre elección de cada individuo, al igual que se condenan las actitudes que atentan contra los derechos y los sentimientos de las personas. La familia se democratiza y se transforma en una comunidad electiva regulada por los sentimientos de cada uno de sus miembros. En el campo higinienista y corporal es manifiesta una clara tendencia a considerar el cuerpo como parte fundamental del bienestar y de la identidad individual, por lo que es objeto de numerosos cuidados y atenciones. El mundo del trabajo contempla el renacer de una nueva ética centrada en la participación, la autonomía y el desarrollo de las personas. En la esfera política, los derechos individuales prevalecen sobre los colectivos. Las religiones basculan desde el dogma a la fe personalizada. La muerte, como en el caso del suicidio o de la eutanasia, es interpretada como un acto voluntario que se inscribe en el ámbito de la soberanía de cada sujeto (Lipovestky, 2003: 39 y ss). Incluso movimientos como los fundamentalistas no son para Lipovestky sino un ejemplo más de esa misma conciencia individualista triunfante (Lipovestky, 1994: 155).

Casi todos los fenómenos, en suma, pueden ser analizados desde la perspectiva de los valores individualistas y hedonistas promovidos por las sociedades de consumo postmodernas.

No obstante, este postmoralismo individualista, poco dado a la sumisión a los valores colectivos, no desemboca, en opinión de Lipovestky, en el desorden o en el vacío moral. Si el imperativo del deber ya no está en boga, en virtud de la erosión del universo moral promovido por la primera modernidad, si lo está en cambio la ética (Lipovestky, 1994: 208). Ahora bien, mientras que la cultura del deber era sacrificial, poniendo en primer término las obligaciones del individuo hacia la comunidad, el mundo de la ética apela sobre todo a la libertad y a la responsabilidad individual.

Esta nueva conciencia ética postmoralista, que producen los valores individualistas pero también los temores de la época postmoderna en relación con 
la destrucción de la naturaleza, con los avances biogenéticos, con los desórdenes financieros, o con unas relaciones económicas y laborales más flexibles e inciertas, (Lipovestky, 2003: 45-65 y ss), se manifestaría en una mayor sensibilidad ecológica, en la creciente preocupación por todo lo relacionado con los avances en el campo de la genética, en la crítica a los medios de comunicación o en la nueva ética laboral y empresarial. Aunque en este último caso, al tiempo que se invoca una mayor libertad e iniciativa individual, se solicita también de los trabajadores un mayor compromiso personal.

Y es que, en efecto, este nuevo código ético postmoderno presenta al lado de una cara más individualista y liberadora otra en la que los sujetos se someten a la labor constante de construcción de sus propias biografías, al carecer de tradiciones que los orienten (Lipovestky, 2003: 27). Todo lo cual es fuente de numerosas angustias e incertidumbres para ellos.

Si en el ámbito de la moral imperan los valores individualistas y más libertarios impulsados por la ideología de los derechos fomentada por la sociedad de consumo, en el terreno de la cultura la influencia del mundo del consumo es todavía mayor si cabe. Asistimos también en este campo a una nueva época, la de la cultura-mundo.

\section{CULTURA-MUNDO: LA CULTURA DE LAS CULTURAS}

Como tantos otros fenómenos de la postmodernidad la cultura también se habría visto influida por las normas y los valores potenciados por el capitalismo de consumo. En efecto, allí donde existía un claro consenso entorno a una cultura mucho más universal y jerárquica, emergería ahora una realidad más proteica, en donde imperan al lado de las tendencias más comerciales, globales y homogéneas, otras que ensalzan lo novedoso, lo particular y lo diverso (Lipovestky, 2010: 7 y ss).

Abundemos un poco más en esos aspectos de la cultura-mundo a las que alude Lipovestky. Según el autor francés la globalización hipercapitalista implicaría la conquista progresiva de la cultura por los mercados (Lipovestky, 2010: 42). Este hecho daría lugar a la difusión, a través de las nuevas tecnologías de la comunicación y de la información, de un mismo estilo de vida a nivel planetario, pero también a la afirmación de los gustos individuales y de las costumbres locales. Dicho de otro modo, la cultura se universaliza y por ello necesita también adaptarse para tener éxito a las particularidades de cada país y a los caprichos del gran público. Y no sólo por los condicionamientos del propio mercado, sino también porque "cuanto más acceden los individuos a la cultura-mundo, más sienten la necesidad de defender su identidad cultural y lingüística" (Lipovestky, 2010: 142). En suma, homogenización capitalista, sí, pero también diversificación e individualización de las orientaciones culturales (Lipovestky, 2010: 126 y ss).

La cultura hipermoderna se integraría así dentro de una gran industria orientada al entretenimiento, al alcance de las masas, a un tiempo homogénea y diversa, y en 
constante transformación, impulsada por unos mercados en permanente renovación de su oferta (Lipovestky, 2010: 79). La cultura adquiere por este camino la categoría de una verdadera moda. Y la moda, a su vez, se transforma en cultura, deshaciendo los viejos esquemas que separaban la alta cultura de la cultura de masas (Lipovestky, 2010: 106 y ss). Todo lo cual tiene que ver más con la "igualación de los comportamientos culturales" que con la degradación de los mismos. En efecto, nos dice Lipovestky, de la cultura actual se puede decir que es tan superficial, homogénea y ligera, como compleja y heterogénea. $Y$ del ciudadano que la consume que es tan conformista, como crítico y reflexivo (Lipovestky, 2010: 158-59).

Este mismo proceso de mercantilización, diversificación e individualización generado por el capitalismo de consumo, produciría al mismo tiempo una realidad cada vez más incierta. Como el secularismo futurista instaurado por la modernidad ya no goza del mismo predicamento, como ya no hay un sentido común que oriente y guíe la vida de los sujetos, como, en suma, ni el mercado ni el individualismo postmoderno han sabido crear mundos de vida suficientemente sólidos y estables, la cultura-mundo produce más desconcierto e inseguridad que confianza y certeza (Lipovestky, 2010: 19-20).

Una de las manifestaciones de este desconcierto generalizado está en la misma libertad de la que hacen gala los sujetos postmodernos. Por un lado, son cada vez más las opciones de las que disponen. Por el otro esta misma libertad porta el germen de la duda y de lo contingente. Se da así la paradoja de que "cuanto más libre y dueño de sí es el individuo, más vulnerable, frágil e interiormente desarmado parece" (Lipovestky, 2010: 61).

La otra se expresa en forma de una verdadera crisis de civilización, uno de cuyos ejemplos más visibles sería el de la educación, por ser la esfera que mejor representa, en el contexto de una sociedad de consumo individualista y hedonista, la deslegitimación de la cultura moderna, y con ella todo el orden disciplinario y autoritario que la sustentaba (Lipovestky, 2010: 169-70).

Para salir de esta incertidumbre en busca de un sentido a todas luces precario, los individuos buscan en muchas ocasiones la evasión del consumo, en otras los consejos terapéuticos y espirituales, y en otras el refugio de comunidades étnicas o tribales. Aunque no es infrecuente que estas mismas válvulas de escape devuelvan todavía más ansiedad y desconcierto (Lipovestky, 2010: 57 y ss).

Así describe Lipovestky las contradicciones de la nueva cultura, influida por un mundo del consumo también altamente contradictorio.

\section{LAS CONTRADICCIONES DEL INDIVIDUALISMO CONSUMISTA: "NARCISO LIBERADO" FRENTE A "NARCISO ENCADENADO"}

La sociedad de consumo, tal como la percibe Lipovestky, supuso un avance sin precedentes en la libertad de elección de los sujetos. Liberados del lastre de la tradición y de vínculos familiares o de clase, los individuos postmodernos 
afirmarían su condición con una autonomía antes desconocida, proyectando sus aspiraciones de igualdad e independencia sobre la variedad de productos y de experiencias que les ofrece el mercado.

Ahora bien, lo paradójico de esta situación, afirma Lipovestky, es que cuanto más progresan los sujetos en la conquista de esa libertad y de esa autonomía en condiciones de igualdad con sus semejantes, más se circunscribe su ejercicio al ámbito del mercado. (Lipovestky, 2007: 42 y ss). Y cuanto más dependientes son de esta esfera para el logro de su bienestar material y espiritual, más desconcertados e insatisfechos se sienten, y más necesidad tienen por ello de nuevos objetos y de nuevas experiencias (Lipovestky, 2007: 118-19). De ahí la constante renovación del mercado de consumo, en respuesta tanto a las estrategias empresariales como a las necesidades nunca plenamente satisfechas de los consumidores.

La sociedad de consumo presenta así dos caras antitéticas, que conforman la personalidad del sujeto hipermoderno. Una despreocupada y feliz, que gusta de los placeres mundanos; la otra más sufriente, acosada por ansiedades y angustias de todo tipo (Lipovestky, 2007: 231). Por un lado, los individuos se entregan al goce sensorial y estético, a una cultura hedonista. Por el otro, experimentan las amenazas derivadas de las aprensiones que generan las preocupaciones por el bienestar y el éxito personal, que conducen a un perfeccionismo sin freno (Lipovestky, 2007: 251). Detrás de este último sentimiento siempre la misma causa; a saber, una cultura consumista que ha debilitado los vínculos colectivos y que ha exacerbado los deseos de bienestar, de felicidad y de superación personal, dejando al individuo sólo frente a sus propias circunstancias (Lipovestky, 2007: 324; 2008: 23).

Precisamente porque el bienestar y la felicidad, la autonomía y la libertad, están cada vez más ligadas a la esfera del consumo, y precisamente también porque a través del consumo los individuos tratan de remediar el malestar que padecen, son cada vez más exigentes y, por eso mismo, también más críticos. Hay que alejar por tanto, sostiene Lipovestky, la imagen que asocia la pasividad con las actuales sociedades de consumo. Al contrario, cuanto más se integra el ciudadano en este mundo, también se hace más reflexivo y por ello también más crítico (Lipovestky, 2007: 130; 2008: 113).

A la cultura del consumo así descrita no es refractaria ninguna clase social, ni los miembros de los grupos más desfavorecidos quieren apartarse de ella. También ellos son "una especie de hiperconsumidores" (Lipovestky, 2007: 184) que desean integrarse en un universo que todo lo envuelve, y que por eso engendra tantas frustraciones, especialmente en los que pretenden formar parte de él pero no pueden (Lipovestky, 2008: 29).

El consumo aparece así en la obra de Lipovestky como un hecho total que estructura el conjunto de la sociedad. Casi todos los fenómenos, sean estos individuales o institucionales, pueden ser analizados refiriéndolos a esta realidad que todo lo abarca. Ámbitos tan diferentes como la política, la educación, el 
deporte o la salud, son permeables a su influencia (Lipovestky, 2007: 252 y ss). Tal es así, que el ensayista francés no duda en emplear el término de consumomundo para aludir a la formidable penetración que ha tenido esta cultura en las sociedades occidentales (Lipovestky, 2007: 193-94).

Este mundo lleno de contradicciones, en el que los individuos persiguen la felicidad y la plenitud sin ninguna estructura colectiva que los coarte. Pero en el que se encuentran también cada vez más ante sí mismos cuanto más persisten en la búsqueda de su bienestar y de su realización personal. Este mundo, afirma Lipovestky, profundamente individualista, democrático y hedonista, y sin embargo también con tendencia a la desestructuración y a la depresión, es el propio de una época que ha traspasado las fronteras de la postmodernidad para entrar en la hipermodernidad.

\section{MÁS ALLÁ DE LA POST-MODERNIDAD: LA HIPERMODERNIDAD}

El adjetivo hiper se ha ido imponiendo en las obras de Lipovestky como un modo de caracterizar la modernidad más avanzada. Aunque es un término que el mismo no ha creado1, sí se puede decir que lo ha convertido en la seña de identidad de sus últimas obras. Todo parece poder ser comprendido bajo el prefijo hiper. Hipercapitalismo, hipertecnología, hiperindividualismo, hiperconsumo, hipercultura y, por supuesto, la hipermodernidad que todo lo engloba. Con este último término precisamente, el autor francés hace referencia al comienzo de una nueva etapa en la que todos los valores encumbrados por la modernidad y que cobraron vida en la postmodernidad, se habrían exacerbado. Las sociedades hipermodernas, dominadas por el consumo, conocerían así un proceso de democratización, individualización y liberación sin precedentes, pero también de las contradicciones que todas estas transformaciones llevan aparejadas en forma de incertidumbres y ansiedades de todo tipo (Lipovestky, 2006: 58-59).

En efecto, la hipermodernidad no sólo habría llevado al extremo el proceso de personalización y de liberación puesto en marcha por la postmodernidad. Habría supuesto asimismo la desestructuración todavía más extrema de todos los órdenes institucionales. Como resultado de este doble proceso de individualización y de desinstitucionalización, la autonomía de los sujetos crece en proporción a su desestabilización personal y a su dependencia del mercado (Lipovestky, 2006: 59-60).

Se da así la paradoja de que liberación y ansiedad caminan de la mano cuando ya no hay trabas institucionales que frenen la expresión de la individualidad, pero cuando no existen tampoco instancias colectivas que mitiguen el temor y la ansiedad de quienes no encuentran respuesta en el orden del mercado. Los sujetos hipermodernos viven así una temporalidad que ya no es la del optimismo futurista de la primera modernidad, ni la del presente confiado y gozoso de la postmodernidad, sino la del "porvenir puro" (Lipovestky, 2006: 71), un futuro pleno 
de urgencias y de incertidumbres que los mismos sujetos han de construir sin nadie que los guíe.

La hipermodernidad habría así acentuado todas las ambigüedades de la sociedad de consumo, creando un escenario en el que los excesos consumistas y hedonistas conviven con las frustraciones y las decepciones más intensas.

\section{CONCLUSIÓN. A MODO DE COMENTARIO CRÍTICO}

La obra de Lipovestky tuvo una enorme proyección internacional. Este hecho se debió sin duda a que es rica en observaciones inteligentes sobre la sociedad contemporánea, a un estilo fácil de digerir para el lector medio ilustrado, menos inclinado a otros escritos de mayor rigor explicativo y científico, y a que juega con el arte de la paradoja, consistente en afirmar una verdad y su contraria con el propósito de captar las ambigüedades de las sociedades contemporáneas. Carece sin embargo de la suficiente apoyatura empírica y, sobre todo, de análisis suficientemente mesurados y profundos (Alonso-Rodríguez Fernández, 2010).

El pensamiento de Lipovestky se ubicarían en la perspectiva individualista, frente a la de aquellos autores que ven proliferar en la sociedad contemporánea manifestaciones comunitarias de todo tipo (Maffesoli, 1990). Todas estas manifestaciones no serían para él, sin embargo, sino la expresión del individualismo imperante en las sociedades actuales (Lipovestky, 1990: 307-315; 2003: 26-27, 2007: 47). ¿"Como no reparar en el hecho- nos dice- de que la pertenencia comunitaria ahora se elige, se reivindica, se pregona ostensiblemente como una manera de ser uno mismo, como un vector de identidad personal?" (Lipovestky, 2007: 205-206).

Lipovestky se alinearía, pues, con aquellos sociólogos, como Beck o Bauman, que ven a las sociedades contemporáneas fuertemente individualizadas y desinstitucionalizadas. Si bien él, a diferencia de Beck, focaliza sus explicaciones en el mundo del consumo con una actitud mucho menos crítica que la de Bauman.

El consumo es, pues, para él el fenómeno que todo lo explica. Aunque no deja de afirmar que la Postmodernidad y la Hipermodernidad son el producto de la evolución de las sociedades modernas (Lipovestky, 1986: 11-12), concede en esta evolución un papel cardinal al consumo. "Lo que caracteriza al hiperconsumo o al consumo-mundo- afirma- es el hecho que incluso lo no económico (Familia, religión, sindicalismo, escuela, procreación, ética) está asediado por la mentalidad del homo consumericus" (Lipovestky, 2006: 129). Y es aquí precisamente donde está a nuestro entender su mayor debilidad, la debilidad de todos sus escritos. Al no reconstruir con rigor la multitud de fenómenos que analiza, al hacerlos depender todos de la causa común del consumo, la sociología de Lipovestky permanece en la superficie de la realidad que explica. Si bien detecta con fina inteligencia intuitiva los distintos aspectos de la sociedad que retrata, no acierta, por lo dicho anteriormente, a dar una explicación coherente de los mismos, remitiendo todos ellos a la misma realidad del consumo que todo lo explica. Así, la 
cultura del consumo es culpable de una cosa y de su contraria. A su influencia se debe el individualismo y la solidaridad, el materialismo y el idealismo, el conformismo y el espíritu crítico, el descanso en los placeres y las ansias de superación, el repliegue al mundo privado y la participación pública, el desconcierto y el sentimiento contrario, la confianza y la seguridad, y, en fin, la felicidad más efusiva y su opuesto, la angustia y el sufrimiento. Todas estas paradojas encuentran respuesta en el espíritu de un consumismo triunfante. Incluso los que se oponen al consumo voraz no son vistos sino como otros consumidores, como personas que optan por formas distintas de consumo (Lipovestky, 2007: 330). Más allá de esta realidad, no se atisban otras razones, otros poderes $u$ otros conflictos emergentes, salvo los derivados de la desestructuración personal y colectiva que produce el individualismo exacerbado, o las frustraciones derivadas de la deficiente integración en el universo total del consumo (Alonso-Rodríguez, 2010). La sociedad de consumo es presentada así como una totalidad que se mantiene en equilibrio, e incluso progresa integrando a las fuerzas que se le oponen (Lipovestky, 2007: 351). Fuera de ella no hay nada, pues, que pueda ser explicado satisfactoriamente. El consumo tiene tanta preponderancia en la obra de Lipovestky, que cualquier cambio que atisba en este ámbito es tomado como ejemplo del advenimiento de una nueva época, a la que se apresura a calificar con otro término.

Ahora bien, si el consumo lo abarca todo o casi todo, no se entiende que el autor francés apele, como remedio para superar este modo vida, a una "ética de las pasiones" orientada hacia actividades influidas a su vez por el consumo (Lipovestky, 2008: 124-25). No se ve, en suma, como podría llegarse a lo que él denomina casi proféticamente, la "democracia posconsumista" (Lipovestky, 2008: 126).

Por lo demás, cuando se trata de juzgar a la sociedad de consumo, de hacer balance de sus beneficios y de sus perjuicios, Lipovestky, aun reconociendo los desarreglos psicológicos que ésta produce, resalta más la libertad que otorga al individuo, proporcionándole mayores opciones e incluso más posibilidades de reconstruir su propia vida. Pues "si bien son numerosas las insatisfacciones y las decepciones" que crea- nos dice- "también lo son las ocasiones de librarse de ellas" (Lipovestky, 2008: 121).

Aun así, lo que más puede sorprender a un lector atento de la obra del ensayista francés, es como alguien que reivindica el legado de Tocqueville en todos sus escritos no haya querido ver que es la modernidad, con todas sus complejidades y vertientes, la que está detrás de muchos de las fenómenos que él analiza, y que para comprenderlos es necesario seguir con paciencia y rigor cada uno de sus hilos, y no remitir todos ellos al mismo universo del consumo que todo lo explica. 
Notas

1 El concepto de hipermodernidad fue empleado por primera vez hace más de 25 años en una obra colectiva dedicada al estudio de una multinacional norteamericana, en la que se calificaba de hipermoderno a un modo de gestión empresarial centrado en el control psicológico de los empleados (Aubert, 2010:15

\section{BIBLIOGRAFÍA*}

2005 ALONSO, L.E, La era del consumo, Ed.SXXI, Madrid

2010 ALONSO, Luís E-RODRIGUEZ FERNÁNDEZ, Carlos J, "Consumo e Hipermodernidad. Una revisión de la obra de G. Lipovestky”, Anuário Filosófico, XLIII/2, 98, Madrid, pp 325-351

2010 AUBERT, Nicole, «Un individu paradoxal », en AUBERT, N (Dir.) L'individu hypermoderne, Éditions Érès, París.

1986 LIPOVESTKY, Gilles (1983) La era del vacío, Ed. Anagrama, Barcelona.

1990 LIPOVESTKY, G (1987) El imperio de lo efímero. La moda y su destino en las sociedades modernas, Ed. Anagrama, Barcelona.

1994 LIPOVESTKY, G (1992) El crepúsculo del deber. La ética indolora de los nuevos tiempos democráticos, Ed. Anagrama, Barcelona

1999 LIPOVESTKY, G (1997) La tercera mujer, Ed. Anagrama, Barcelona.

2003 LIPOVESTKY, G (2002) Metamorfosis de la cultura liberal. Ética, medios de comunicación, empresa, Ed. Anagrama, Barcelona

2004 LIPOVESTKY, G-ROUX, E (2003) El lujo eterno. De la era de lo sagrado al tiempo de las marcas, Ed. Anagrama, Barcelona 
2006 LIPOVESTKY, G-SÉBASTIEN, CH (2004) Los tiempos hipermodernos, Ed. Anagrama, Barcelona

2007 LIPOVESTKY, G (2006) La felicidad paradójica, Ed. Anagrama, Barcelona. 2008 LIPOVESTKY, G (2006) La sociedad de la decepción, Ed. Anagrama, Barcelona.

2009 LIPOVESTKY, G-SERROY, J (2007) La pantalla global, Ed. Anagrama, Barcelona

2010 LIPOVESTKY, G-SERROY, J (2008) La cultura-mundo. Respuesta a una sociedad desorientada, Ed. Anagrama, Barcelona

1990 MAFFESOLI, Michel, El tiempo de las tribus, Ed. Icaria, Barcelona

1998 MARTÍNEZ BARREIRO, Ana, "La moda en las sociedades avanzadas", Papers 54, ISSN 0210-2862, Barcelona, pp 129-137

2006 MARTÍNEZ BARREIRO, A, "La difusión de la moda en la era de la globalización", Papers 81, ISSN 0210-2862, Barcelona, pp 187-204

2005 ROMERO RECHE, A, "La producción especializada del discurso humorístico en un entorno cultural postmoderno", REIS 109, ISSN 0210-5233, Madrid, pp 75126

2010 RUÍZ SÁNCHEZ, José Carlos, De Guy Debord a Gilles Lipovestky: el tránsito de la categoría de lo social a la categoría de lo individual, Ed. Servicio de Publicaciones de la Universidad de Córdoba, Córdoba

2011 SENNETT, Richard, El declive del hombre público, Ed. Anagrama, Barcelona.

1993 TOCQUEVILLE, Alexis De, La democracia en América, Ed. Alianza Editorial, Madrid.

* Se indican entre paréntesis las fechas de la edición original de las obras de Lipovestky. En el cuerpo del texto se cita sin embargo por el año de la edición española. 